\section{BIBLIOTECONOMIA, CIÊNCIA E FILOSOFIA: \\ um debate necessário sobre teoria e prática no campo acadêmico-científico}

\author{
Diego Salcedo* \\ Marcílio Bezerra Cruz
}

\begin{abstract}
Parte do pressuposto e da observação em sala de aula, nas disciplinas sobre pesquisa, ciência e filosofia ofertadas no Curso de Biblioteconomia da Universidade Federal de Pernambuco, de que boa parte dos estudantes demonstra certa dificuldade ou resistência no modo de entender a relação entre a teoria e a prática no cerne do campo acadêmico-científico. Tem como objetivos propor um debate a respeito das relações teóricopráticas no interior das pesquisas científico-acadêmicas, bem como contribuir com a produção de bibliografia didática para uso dos estudantes. $O$ debate está dividido em três seções: analisa tanto o desenvolvimento histórico do racionalismo e do empirismo quanto as suas influências na estrutura das pesquisas acadêmicas e científicas; indica como o idealismo alemão (na filosofia) e o positivismo (na ciência) promoveram uma cisão entre a teoria e a prática; e examina essa herança de pensamento bipartido no contexto brasileiro. Pesquisa de caráter exploratória utilizou a metodologia de revisão bibliográfica. Aponta como consideração final que 0 senso comum tem como herança a opinião, principalmente dos estudantes que ingressam na universidade, de que o fazer científico não possui relação estreita com algumas atividades acadêmicas. Considera também que as atividades acadêmico-científicas indicam a polarização entre a teoria e a prática, opinião inadequada na contemporaneidade.
\end{abstract}

Palavras-chave: Biblioteconomia. Ciência. Filosofia. Prática. Teoria.

\footnotetext{
* Doutor em Comunicação pela Universidade Federal de Pernambuco, Brasil. Professor Adjunto no Departamento de Ciência da Informação da Universidade Federal de Pernambuco, Brasil. Coordenador do Grupo de pesquisa IMAGO.

E-mail: salcedo.da@gmail.com.

* Licenciado em Filosofia pela Universidade Federal de Pernambuco, Brasil. Mestrando no Programa de PósGraduação em Filosofia da Universidade Federal de Pernambuco, Brasil.

E-mail: mbc_cilio@hotmail.com.
}

\section{INTRODUÇÃO}

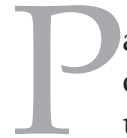

arece haver no senso comum uma opinião de que a ciência, embora tendo um papel destacado na organização das grades curriculares dos cursos de graduação e pós-graduação das universidades brasileiras, não possui uma estreita relação com algumas atividades acadêmicas - apresentando muito mais uma ruptura do que, de fato, uma conexão. Alguns seguem uma perspectiva que situa a pesquisa científica como atividade prática e com fins sociais. Por sua vez, outros entendem a pesquisa acadêmica como exercício mais teórico e especulativo.

Entretanto, a dicotomia difundida por meio desse imaginário popular pode estar equivocada, se considerado o seguinte: a cisão entre a prática e a teoria, no interior das atividades de pesquisas científicas ou acadêmicas, é inexistente. Por um lado, as teorias científicas, que podem sugerir atividades apenas conceituais, se definem a partir das "relações entre os fatos" (SANTOS, 2012, p. 117), isto é, elas são construídas por meio da organização dos fenômenos no mundo.

Por outro lado, existem certas atividades acadêmicas que são caracterizadas como práticas 
sociais: é o caso, por exemplo, das ações extensionistas que "[...] viabilizam a interação entre a universidade e a sociedade e que constituem um elemento capaz de operacionalizar a relação teoria/prática" (FÓRUM NACIONAL DE PRÓ-REITORES, 2000).

Deste modo, o equívoco está na atitude de encarar a ciência e a universidade como entidades polarizadas e na crença de que as atividades praticadas numa esfera não têm relação com a outra. Essa interpretação decorre da compreensão de mundo bipartido, entre razão e sensação, que parece encontrar resquícios desde a Antiguidade até o final do século XVIII, resultando, assim, num dos principais paradigmas epistemológicos da Modernidade. Contudo, as atividades acadêmicas são também produções científicas e que muitas dessas produções pressupõem atividades acadêmicas. Há, portanto, uma correlação que passa muitas vezes despercebida pela comunidade acadêmica e que necessita ser explorada.

Como sugere Geogen (1998), as atividades acadêmicas podem ser divididas, grosso modo, tanto no horizonte das pesquisas científicas quanto na formação de novos profissionais. Mas essa divisão, longe de ser uma realidade, deve ser entendida como um modo didático de compreender a estrutura de algumas das atividades realizadas na universidade. Ambas não se encontram dissociadas, mas se complementam: os instrumentos necessários para a profissionalização do estudante de graduação e de pós-graduação, por exemplo, são oriundos das pesquisas científicas e a continuidade de tais pesquisas está pautada com o surgimento e seleção de novos profissionais.

Ainda e para além da construção profissional de cada estudante a pesquisa científica possui a qualidade de

\begin{abstract}
se tornar peça chave da formação dos indivíduos, os preparando para a 'guerra' diária que requer um olhar científico e indagador, e a experiência com a pesquisa científica traz à tona todo esse potencial humano, pois o processo de aprendizagem é de extrema complexidade (NERVO; FERREIRA, 2015, p. 32).
\end{abstract}

Do mesmo modo ela também produz importantes contribuições para o desenvolvimento da ciência. Utilizando métodos e técnicas de investigação, a pesquisa científica se caracteriza:

\begin{abstract}
por ter base em processo cumulativo e não ser um produto pronto, dado como verdade única e eterna. Por outro lado, reveste-se de conhecimento em permanente movimento. Constitui verdade provisória e produz ciência ou deriva de parte dela (SANTOS, 2010, p. I4I).
\end{abstract}

Assim, ao contrário de serem aspectos diferentes de uma mesma realidade (teoria e prática), a ciência e a universidade são realidades distintas com características similares (teóricopráticos). Suas finalidades convergem na medida em que buscam fazer uso do conhecimento para trazer algum retorno aos problemas vigentes da sociedade (GEOGEN, 1998). Por exemplo, os eventos acadêmicos e científicos aparecem como atividades que visam tanto à interação e troca de informação por parte dos pesquisadores quanto à divulgação e disseminação dos avanços científicos a sociedade.

Exposta essa problemática, o objetivo principal do artigo é propor um debate sobre as relações teórico-práticas que ocorrem no interior das atividades de pesquisas científicoacadêmicas, como forma de esclarecer algumas incoerências suscitadas pela compreensão bipartida de mundo que desembocou no imaginário popular de que as atividades teóricas não possuem qualquer relação com as práticas.

Em um primeiro momento vamos analisar tanto o desenvolvimento histórico do racionalismo e do empirismo quanto as suas influências na estrutura das pesquisas acadêmicas e científicas da contemporaneidade. Depois, será discutido como o idealismo alemão (na filosofia) e o positivismo (na ciência) promoveram uma cisão entre a teoria e a prática nas atividades humanas do século XVIII e XIX. Na terceira seção do trabalho, examinaremos como o Brasil está imerso nessa discussão, buscando ressaltar os elementos que contribuíram para a construção do imaginário popular de que a ciência e a universidade não possuem, de fato, uma relação intrínseca.

Por fim, vale ressaltar que a ideia para a construção deste artigo surgiu a partir das leituras e debates no Grupo Imago, bem como da atividade docente dos autores nas disciplinas 
de Introdução à Filosofia, Biblioteconomia e Pensamento Científico e Metodologia do Trabalho Científico, todas oferecidas no Curso de Biblioteconomia na Universidade Federal de Pernambuco (UFPE).

Durante o semestre letivo os alunos mostraram certa dificuldade em considerar outra forma de visão de mundo, que não a bipartida, sendo possível observar alguma resistência destacada no modo de entender a relação teoria e prática no interior de algumas atividades acadêmicas.

Com o intuito de contribuir para a atualização da bibliografia didática para o curso supracitado a elaboração deste texto é resultado de metodologia caracterizada como exploratória em relação ao objeto e bibliográfica em relação ao procedimento. Por fim, a seção a seguir inicia o debate a partir do florescimento de certo tipo de pensamento, por sua vez, desembocando numa clivagem entre razão e sensação.

\section{A COMPREENSÃO BIPARTIDA DE MUNDO}

Não é possível precisar o momento exato em que o homem elaborou pela primeira vez o pensamento científico, embora costume-se atribuir o florescimento da ciência em paralelo ao advento da filosofia (RONAN, 1987). Nesse sentido, os primeiros filósofos encontraram um novo modo de responder as suas incertezas, a partir da organização mental dos fatos observados na natureza, em divergência com o pensamento mítico. Este prevalecia como a única possibilidade de resposta às dúvidas suscitadas pelos fenômenos do mundo.

Tales de Mileto, a quem a tradição filosófica desde Platão e Aristóteles atribuiu o título de "primeiro dos filósofos", é também o "primeiro dos cientistas". Promoveu Tales uma gradativa cisão com o pensamento mítico abrindo mão das respostas vigentes em seu tempo para, por meio da observação da natureza, atribuir ao elemento água, o princípio de todas as coisas.

Com ele se inaugura uma tradição em que as respostas não são mais baseadas apenas em crenças, mas por meio da observação dos fenômenos e na concatenação do pensamento. Pensamento e observação surgem como características que organizam e diferenciam a filosofia e a ciência do mito. É por conta disso que, em suas origens, filosofia e ciência não devem ser entendidas como coisas distintas, mas como modo único de compreender a realidade.

Como argumenta Rosa (2012, p. 120-121) é mister:

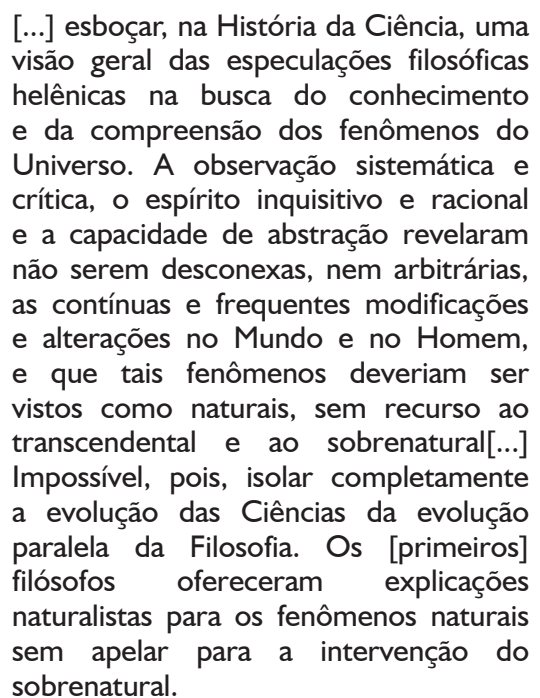

Todavia, há um costume equivocado por parte de alguns comentadores de estabelecer uma separação entre ambas no interior do pensamento helênico. Essa leitura é centrada na opinião de que os gregos encaravam a filosofia e a ciência como atividades distintas - sendo a primeira, essencialmente, teórica e a segunda prática.

Mas, como argumenta Hadot (2011), a vida nas cidades gregas estabelecia a configuração existencial dos seus cidadãos, isto é, toda a energia era voltada para uma melhoria na organização da polis, pois, somente em seu interior, a excelência humana era possível.

Não havia, portanto, qualquer pensamento teórico que não tivesse a pretensão de ser aplicado. O conceito de vida contemplativa (bios theoretikós, no grego), por exemplo, longe de significar uma vida voltada exclusivamente ao ócio e a contemplação, era entendida como o ideal de realização da teoria na prática.

Os pitagóricos não tiveram a pretensão de elaborar suas teses acerca dos entes matemáticos, apenas, para guardá-las no interior de sua comunidade esotérica. Muitos, inclusive, participaram ativamente da vida pública, aplicando seu conhecimento na organização e na melhoria de suas cidades (KAHN, 2007). 
Do mesmo modo, Parmênides e os seguidores, conquanto a tradição tenha-lhes atribuído a origem de um pensamento metafísico e centrado nos aspectos do Ser, também deram importantes contribuições para a política: Casertano (2007), citando Capizzi (1975), é um exemplo de como é possível ler o poema de Parmênides como um elogio metafórico a organização da cidade de Eleia.

Para além da relação teoria e prática, razão e sensação ou pensamento e observação, também não eram modos distintos de compreender a realidade. Por mais que um pensador pudesse ser inclinado a uma corrente metafísica ou materialista de filosofar, sempre era possível encontrar resquícios de ambas no interior de suas obras. É o caso de Platão e Aristóteles: há uma crença (igualmente equivocada) de que podemos ler as suas obras por meio da querela racionalismo vs. empirismo. Mas essa compreensão é apenas um modo moderno de entendê-los, isto é, uma forma anacrônica de estudar seus pensamentos.

Por séculos, os antigos foram lidos por meio de uma interpretação cristã que procurava estabelecer uma conexão entre a tradição semita e a indo-europeia. A teoria das ideias de Platão, por exemplo, é quase sempre lida como o expoente de uma doutrina metafísica e, por conseguinte, do pensamento. O filósofo ficou conhecido por um pensamento transcendental que encarava a realidade do mundo de modo polarizado: de um lado, a realidade aparente do mundo sensível que estava envolvida num profundo devir (a mistura do Ser com o não-Ser) e de outro, a realidade efetiva do mundo suprassensível que era a morada das ideias inteligíveis.

Essa polarização foi possível porque os primeiros padres da igreja utilizaram os diálogos do filósofo para fundamentar racionalmente as doutrinas eclesiásticas: o demiurgo no Timeu se tornou o preâmbulo ao Deus cristão; a psique socrático-platônica se tornou a alma do povo cristão e a crítica ao modo hedonista de viver, se tornou a prática de autoflagelo que condenou o corpo por tantos séculos. Contudo, a sensação, ao contrário da habitual leitura feita nos manuais de História da Filosofia, também é um elemento importante para a filosofia de Platão e não pode ser deixado de lado.

No diálogo Fédon (2015, p. 248), lemos:
[...] não admito de modo algum que aquele que investiga as coisas que são mediante 0 discurso racional [pensamento] está lidando com imagens mais do que aquele que as investiga observando os fatos da vida cotidiana [observação].

Aristóteles, por seu turno, mesmo sendo descendente da tradição médica que, conforme explicita Cornford (1989), era a corrente mais próxima de um "empirismo moderno" na Antiguidade, não deixava de revelar resquícios de uma racionalização em suas obras. Seu pai era Nicómaco, um médico importante do séquito do rei Amitas II, avô de Alexandre Magno.

A paixão pela natureza e o seu distanciamento da Matemática são características herdadas do seu pai. Os livros que compõem a Metafísica, por exemplo, empregam conceitos que migram amiúde da sensação à razão e viceversa, complementando-os mutuamente: o conceito de sínolo, que é a composição dos entes por meio da união de forma e matéria, talvez ilustra bem essa interação. Para Aristóteles o homem só existe enquanto a sua alma (forma) for parte do seu corpo (matéria); a separação dos dois desencadeia na morte de ambas as partes:

[...] ora, observa o Estagirita, os corpos vivos têm vida, mas não são vida. Assim, são como que o substrato material e potencial do qual a alma é 'forma' e 'ato'. Temos assim a célebre definição de alma, que tanto êxito alcançou: 'E necessário que a alma seja substância como forma de um corpo físico que tem vida em potência; mas a substância como forma é enteléquia ( $=$ ato); a alma, portanto, é enteléquia de um corpo assim. [...] Portanto, a alma é enteléquia primeira de um corpo físico que tem a vida em potência'. (REALE; ANTISERI, 1990, p. 197-198).

Foi somente na Idade Média, com o advento de um pensamento com características essencialmente cristãs, que a filosofia e a ciência, a teoria e a prática, a razão e a sensação, tiveram, de fato, sua primeira ruptura. A crença num Deus transcendental, que criou todas as coisas a partir do nada, e a possibilidade de conhecer seus atributos (onipresença, onipotência e onisciência), exclusivamente, por meio da leitura da Bíblia, inviabilizou a observação e o estudo da natureza (por ela mesma). As dúvidas que cercavam o 
homem acerca dos fenômenos naturais não deveriam mais ser esclarecidas por meio da organização mental dos fatos observados, mas por meio da instrumentalização da razão diante da autoridade bíblica e eclesiástica (GILSON, 2013).

Por treze séculos o pensamento científico dos gregos sobreviveu no oriente por meio dos árabes e quando retornou não foi aceito de imediato. A crença e a razão estavam associadas de tal maneira que demorou para aceitá-lo e a modernidade surgiu como filha dessa bipartição: de um lado, o racionalismo metafísico e cristão de René Descartes e do outro, o empirismo cético de Francis Bacon.

Do primeiro, a filosofia adquire o cogito (ou a descoberta da existência de um sujeito como fundamento basilar de toda e qualquer pretensão metafísica) que irá norteála até fins do século XIX; do segundo, a ciência acrescenta à observação dos fenômenos naturais a experimentação. Os gregos não faziam experiências na tentativa de forçar a natureza dizer o que eles queriam; eles apenas a observavam, tirando daí suas hipóteses.

Descartes e Bacon faziam ciência, mas os métodos utilizados manifestavam uma profunda cisão entre ambos os lados:

\section{[...] embora concorde com Descartes quanto a necessidade de estabelecer um método para ciência, ou mais precisamente a instauração de uma nova ciência, discorda completamente desse quanto a natureza do método. O método de Bacon é essencialmente prático e consiste em coligir materiais, executando experiências em grande escala e procurando os resultados na grande massa de provas - um método essencialmente indutivo[...] Enquanto para Bacon, a experiência é o ator principal, no esquema cartesiano, a experiência é um mero ator coadjuvante e auxiliar do pensamento dedutivo (GERMANO, 201 I, p. 85).}

O racionalismo descarta a experiência por acreditar que ela é a fonte de todos os erros. Para um seguidor dessa corrente epistemológica, a elaboração e a manutenção de um pensamento teórico é o suficiente para alcançar a verdade de uma dada realidade. O empirismo, ao contrário, acredita que todo o conhecimento é advindo da experiência sensorial e somente é por meio dela que se é possível elaborar um juízo de valor. A maior parte da filosofia moderna, que permaneceu por muitos séculos presa à metafísica do período cristão, tomou para si o caminho do racionalismo, enquanto que a ciência desse período, por não encontrar abertura para o diálogo, seguiu o empirismo:

\begin{abstract}
[...] pode-se dizer que houve, na construção da racionalidade científica moderna, um predomínio das ideias de inspiração empirista em detrimento ao racionalismo - ainda que se encontrem, na ciência moderna, traços característicos dos dois métodos. Isto porque o mecanicismo - tornado ideal metodológico da ciência moderna a partir da síntese newtoniana - tem inspiração fundamentalmente empirista, uma vez que parte de problemas postos pela realidade e tem como finalidade última não só a explicação do mundo, mas também sua dominação pelo homem, transformando-se em um projeto de cunho pragmático, e não somente intelectual (PIMENTEL, 20I3, p. 37).
\end{abstract}

Em paralelo ao desenvolvimento da ciência na modernidade, as universidades ganharam novas dimensões. Do século XVIII ao XIV, o pensamento teórico (teológico e metafísico) foi predominante na organização das grades curriculares das universidades medievais. O Trivium e o Quadrivium, as artes liberais da época, designavam os sete ramos do conhecimento (Lógica, Gramática, Retórica, Aritmética, Música, Geometria e Astronomia) que iniciava o jovem da Idade Média numa vida de aprendizagem, não abriam possibilidades para o estudo das ciências naturais: a astronomia/astrologia, por exemplo, por mais que sugerisse estudar os corpos celestes, era uma atividade realizada por meio de cálculos e projeções, e não pelo emprego de observações e experimentações.

Deste modo, quando as novas descobertas científicas começaram a se desenvolver no fluxo da modernidade, as universidades não conseguiram acompanhá-las. Os cientistas modernos tiveram que construir suas próprias academias e sociedades científicas para a troca e disseminação de informação entre os seus membros (REALE; ANTISERI, 2007).

$\mathrm{O}$ racionalismo e o empirismo continuaram seguindo caminhos distintos até fins do século XIX. 
O esplendor da modernidade marcou tanto o surgimento de uma filosofia com pretensões universais quanto uma ciência essencialmente progressista e utilitarista. A filosofia encontrou seu ápice nas universidades alemãs com o idealismo proposto por Ficht, Schelling e, em especial, Hegel.

As academias modernas, por outro lado, descendentes das revoluções científica e industrial, moldaram o perspectivismo científico em prol da produção. Mesmo exigindo uma interação necessária entre a teoria e a prática, ambas se tornaram etapas distintas do pensamento; o filósofo natural passou a ser chamado de cientista e a ciência tomou o lugar da filosofia e da religião no que diz respeito a busca pela verdade.

\section{O MITO DO PROGRESSO POSITIVISTA E O IDEALISMO ALEMÃO}

Do pensamento filosófico no esplendor da modernidade (séculos XVII-XVIII), se destaca a crítica de David Hume em relação a toda filosofia com pretensões metafísicas. Para o empirista britânico o conhecimento humano é adquirido por meio da experiência, legando à crença o papel de entender o mundo para além dos seus próprios fenômenos. Em outras palavras, a razão só possui o papel de organizar as sensações, não podendo construir, por si mesma, qualquer tipo de conhecimento.

A matemática, que é o expoente máximo de um pensamento racionalista, não é uma ciência que oferece ao homem novas respostas. Sua atividade se resume em oferecer maneiras distintas de se dizer o mesmo, por exemplo: dizer que $2+2=4$, é dizer, também, que $4=4$; do mesmo modo, dizer que todo triângulo é uma figura geométrica que possui três lados e três ângulos é dizer, em outras palavras, que todo triângulo é um triângulo.

Essa crítica vai repercutir, sobretudo, na lei de causa e efeito. Para o filósofo empirista, de uma causa qualquer não ocorrerá, necessariamente, um dado efeito. Por mais que os fenômenos pareçam ser intrínsecos, nossa experiência nunca será capaz de atestar que eles têm, de fato, uma relação.

Ora, tanto a filosofia quanto a ciência foram construídas tomando como base a lei de causa e efeito. Vejam, por exemplo, Espinoza e Newton: o primeiro foi um filósofo racionalista que construiu toda sua obra a partir dos padrões geométricos euclidianos, isto é, por meio de leis, axiomas, premissas e conclusões, tinha a lei de causa e efeito como ponto fundamental de sua filosofia; o segundo, sendo um dos mais importantes cientistas de todos os tempos, trouxe importantes contribuições para a ciência moderna a partir da lei de ação e reação que são, mutatis mutandis, outras palavras para causa e efeito.

A crítica de Hume, portanto, impossibilita a existência de verdades a partir da filosofia e da ciência, pois, a base que as fundamenta não é a concatenação do pensamento lógico-racional ou a observação e experimentação dos fenômenos naturais (como querem), mas a crença extraída de um hábito. $\mathrm{O}$ fato do Sol sempre nascer no dia seguinte não significa que isso acontecerá amanhã (ou depois e depois e depois...), mas existe a expectativa e, até, a crença de que o evento tornará a se repetir mais uma vez e indefinidamente.

Nesse sentido, propõe Hume (1973, p. 145):

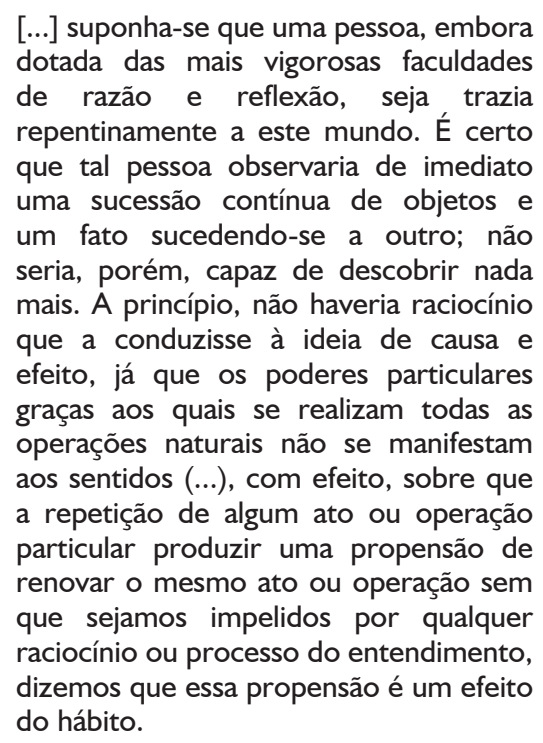

É a partir da crítica proposta por Hume que se faz necessária uma articulação entre o racionalismo e o empirismo no interior do pensamento filosófico. Kant, em sua Crítica da Razão Pura, elabora o que irá se tornar a concepção epistemológica mais importante da humanidade - ele mesmo parecia ter consciência desse fato quando, no Prefácio à 
segunda edição da obra, afirmou que sua tese é similar a "revolução copernicana" na história da astronomia (FERREIRA, 2012). Para o filósofo de Konigsberg, conhecemos o mundo por meio da experiência (como queriam os empiristas), mas isso não significa que não exista, em nós, elementos que independem dela (como querem os racionalistas).

Toda nossa compreensão é dada pelos conceitos de tempo e de espaço, mas essas categorias não são conhecidas por meio da experiência. Os nossos sentidos não são capazes de apreender a sucessão dos eventos (suas causas e seus efeitos), nem as dimensões espaciais que os cercam. Assim, embora extraiamos nosso conhecimento do mundo por meio das sensações e das experiências, os objetos que conhecemos apenas são possíveis de conhecimento porque nossa razão organiza o ambiente de acordo com a nossa constituição (humana e limitada). Em palavras gerais, "podemos dizer que das coisas só conhecemos a priori (independente da experiência) aquilo que nós mesmos colocamos nelas" (ZATTI, 2007, p. 26).

A conclusão se mostrou a mesma do lado da ciência: a revolução científica só se tornou possível por meio da interação entre o racionalismo e o empirismo. Embora Copérnico, por meio de um pensamento hipotético oriundo desde os gregos (HEATH, 1981), tenha elaborado as bases da teoria heliocêntrica, sua comprovação só foi possível graças à observação dos fenômenos celestes efetuada por Galileu e uma luneta.

O desenvolvimento da ciência proporciona a elaboração e novas hipóteses, mas sua efetividade só se torna possível em função da experimentação e aplicação. A física, ciência moderna por excelência, pode ser definida como a aplicação da matemática na natureza, isto é, a ciência que utiliza pensamentos abstratos e conceituais em realidades concretas e efetivas. Como sugere Salcedo (2010, p. 32), “a prática científica, a partir do século XVII, deixa de ser uma atividade, exclusivamente, filosófica" e caminha numa direção de polarização em relação à ciência.

Na filosofia do século XIX, o Idealismo alemão, oriundo da revolução epistemológica proposta por Kant, ganhou contornos metafísicos assombrosos com a figura de Hegel. A ambição do filósofo era tamanha que ele elaborou um sistema que tinha pretensões de responder a todas as dúvidas já suscitadas pelo homem desde os tempos mais remotos. O pensamento abstrato e racional nunca antes ganhou uma dimensão tão universal ao ponto de relacionar a história da humanidade à própria história do pensamento; nunca antes o pensamento teórico e conceitual havia dominado tanto a filosofia como acontecera com Hegel.

Já na ciência, o positivismo formulou o mito do progresso científico como ponto norteador do desenvolvimento humano. Seu nascimento é oriundo do movimento iluminista do século XVIII, que buscou reformular a história a partir de uma superação dos paradigmas estabelecidos pela igreja no período do medievo. Dentre as teses mais conhecidas do positivismo se destaca a afirmação de que uma teoria científica, para ser aceita, necessita ser comprovada por meios dos métodos científicos.

Há, portanto, uma supervalorização de uma ciência empirista que, seguindo a esteira de Bacon e Hume, considerava como crença todo o tipo de conhecimento que não fosse oriundo da experiência. Fazer ciência, nesses termos, significava aplicar os métodos adequados de análise e experimentação da natureza na busca pela verdade.

Póvoa, Gouvea, Bataglia e Teixeira (2012, p. 5) comentam que o positivismo

[...] advogava a superioridade da ciência
empírica relativamente à busca da
verdade, sendo esta sustentada pela
observação, que garantia o confronto
com a realidade. A observação era "a
única capaz de exercer um controle
objetivo nas hipóteses científicas e de
servir de pedra de toque para a sua
verdade ou falsidade".

Ademais, o positivismo contribuiu para a formação de uma ciência utilitarista que pregava a autossuficiência do indivíduo e promovia uma maior fragmentação dos grupos sociais em prol do desenvolvimento científico e econômico. Se a modernidade surgiu, no século $X V$, como um movimento humanista resgatado do período clássico dos gregos, ela se transformou, no século XIX, na mecanização das ações humanas e na subordinação dos seus sentimentos.

O cientificismo, a revolução industrial e o avanço tecnológico moldaram uma imagem da ciência na modernidade que perdurou até a 
contemporaneidade: a tecnociência, como chama Bazannella (2010, p. 31), “[...] vive sob a égide dos imperativos, da busca de respostas práticas e imediatas para as necessidades humanas, sejam elas no campo da economia, produção, do consumo, sejam elas nas esferas das relações humanas".

Diante do radicalismo encontrado tanto pelo idealismo alemão quanto pela tecnociência do positivismo, algumas universidades e academias modernas adquiriram a necessidade de reformular suas concepções. A primeira instituição que se constituiu como uma universidade moderna foi a de Berlim, em 1808, que procurou elaborar uma grade curricular que valorizasse os lados teórico e prático da ciência (PEREIRA, 2008). Embora marcada pelos pensamentos filosóficos idealistas, a universidade de Berlim e seus idealizadores (sobretudo Humboldt), pensaram numa instituição que além de valorizar o pensamento conceitual do indivíduo, pudesse oferecer um maior enriquecimento moral e científico.

Os princípios essenciais postulados por Humboldt são até hoje defendidos como as "premissas que dão a universidade seu caráter próprio". São eles:

[...] a formação através da pesquisa; a unidade entre o ensino e pesquisa; a interdisciplinaridade; a autonomia e a liberdade da administração da instituição e da ciência que ela produz; a relação integrada, porém autônoma, entre Estado e Universidade; a complementaridade do ensino fundamental e médio com o universitário (PEREIRA, 2008, p. 3I).

Embora o modelo proposto por Humboldt tenha recebido destaque no século passado, o modelo francês, construído a partir de uma ênfase mais utilitarista, foi o que predominou na maioria dos países europeus e latino-americanos. O mito do progresso, amplamente difundido durante o período positivista da ciência, instaurou a crença de que a ciência iria levar o homem ao ápice do seu desenvolvimento.

As universidades que seguiram esse modelo organizaram os conteúdos curriculares por meio de uma separação entre seus conteúdos - dando uma maior ênfase aos práticos e científicos. Enquanto a proposta de Humboldt priorizava uma associação programática entre o ensino e a pesquisa científica, o modelo francês promoveu uma ruptura enfatizando apenas um dos dois lados.

Vale ressaltar, entretanto, que além da existência desses dois modelos, outros dois coexistiam: o idealista e o funcionalista. $\mathrm{O}$ primeiro, seguindo na esteira do racionalismo, se fundamentava em uma educação voltada ao desenvolvimento do intelecto, isto é, na organização de uma unidade de ensino que auxiliava a razão na busca pela verdade. O segundo encarava a universidade "[...] com a função de servir a nação e a finalidade de ser de utilidade coletiva, sociopolítica e socioeconômica" (PEREIRA, 2008, p. 32). O modelo funcionalista foi adotado pelos países socialistas que tendem a enxergar as universidades como instrumentos para a formação de novos profissionais e cidadãos engajados com a política.

No Brasil, a relação entre racionalismo e empirismo, entre teoria e prática, não foi tão bem discutida. Do sincretismo cultural com os portugueses à imanência de um politeísmo nativo da região sucumbiu a transcendência de uma metafísica cristã. $O$ racionalismo prevaleceu dominante por mais de três séculos desde o seu ingresso, enquanto se configurava as características de uma cultura essencialmente brasileira.

Somente a partir do século XVIII é que o empirismo aparece como alternativa subjacente ao utilitarismo científico e ao mito do progresso - que inviabiliza qualquer tipo de diálogo por ambas as partes. É assim que no imaginário popular do povo brasileiro, a crença na epistemologia bipartida de mundo ganhou destaque e repercutiu como verdade até os dias atuais, tema tratado na seção seguinte.

\section{O PENSAMENTO BIPARTIDO NO CONTEXTO BRASILEIRO}

A chegada dos jesuítas, em 1549, e o processo de catequização dos índios padronizou o que viria a se tornar o pensamento brasileiro. $\mathrm{O}$ que antes era costume e prática imanente aos povos indígenas foi transformado por uma visão de mundo monopolizada a partir de uma metafísica transcendental e cristã. 
Há razões para se acreditar que a concepção de mundo dos povos indígenas era similar à dos gregos antigos. Acreditava-se na existência de uma alma imortal e que a morte seria apenas a passagem de um modo de existir a outro (ASSINTEC, 2007). Todavia, essa alma não iria para um plano transcendental. Todo o processo que ocorria na passagem de um corpo ao outro (o que os gregos nomearam de metempsicose) era realizado nesse mundo. Só havia um plano existencial para os vivos e para os mortos.

Ora, uma religião que não separa a alma e o corpo em planos distintos inviabiliza a possibilidade de uma compreensão de mundo bipartida. Razão e sensação não fazem parte de realidades distintas, mas são modos diferentes de compreender a mesma realidade. Quando os padres jesuítas catequizaram os índios e difundiram a religião cristã a todo território brasileiro, contudo, eles não só trouxeram consigo a discussão do racionalismo vs. empirismo, como também delimitaram a vitória, apenas, a um dos dois lados.

Somente no século XVIII, com a expulsão dos jesuítas, por parte do Marquês de Pombal, o cenário passou a mudar. Todavia, a presença dos jesuítas permaneceu influente até fins do século XIX e, em algumas regiões do país (em especial no Sul), o pensamento racionalista prevaleceu na vanguarda da política e da ciência até os dias atuais.

Aqueles que possuem um olhar mais utilitarista da ciência consideram que, até inícios do século $X X$, não houve qualquer pensamento científico no Brasil. Isso porque, para os que defendem essa forma de pensamento e ação os jesuítas pregaram características do racionalismo cristão como a única forma possível de conhecimento.

Fleck (2014, p. 672), citando Ferraz e Figueroa (1995, p. 209), propõe que:

\footnotetext{
[...] se considerarmos a produção historiográfica brasileira sobre ciência e ilustração na América, constataremos que "certas concepções teóricas e metodológicas vigentes até bem pouco [tempo] buscavam encontrar atividades científicas em tudo [utilitarismo científico] exatamente semelhantes às europeias... considerando evidência de que aqui só houve ciência a partir do século $X X "$.
}

As universidades brasileiras, até $\mathrm{o}$ século passado, eram de matriz jesuíta, isto é, tinham a influência do racionalismo como modo predominante na estrutura das grades curriculares. O modelo de universidade moderna, com uma maior uniformidade dos conteúdos acadêmicos emerge no país com a organização da Universidade de Brasília em 1962, até lá (e mesmo depois), o que se manteve foi a separação entre o ensino, a pesquisa e a extensão, oriunda da compreensão epistemológica bipartida que instaurou o pensamento equivocado de que razão e sensação, teoria e prática são coisas separadas:

[...] no Brasil, são raras hoje as instituições de educação superior com um programa que, de fato, vincule o ensino com a pesquisa. Mesmo naquelas em que essa vinculação é defendida, frequentemente essa vinculação é dificultada por um corpo docente pouco engajado com o desenvolvimento de pesquisas. $O$ que temos na grande maioria das universidades brasileiras é uma 'universidade de ensino' apenas, que, embora possa desempenhar um papel importante no país, não é legitimamente 'uma universidade de ensino e pesquisa' (PEREIRA, 2008, p. 34).

A modernização do ensino superior brasileiro, como menciona Souza (1996, p. 55), “começou com a criação do Instituto Tecnológico da Aeronáutica (ITA) e culminou com a criação da Universidade de Brasília (UNB), nascida de um planejamento de institutos, escolas e centros e não da justaposição de Faculdades isoladas". O que parecia dar início ao progresso no interior das universidades brasileiras logo foi ofuscado por meio da implementação da Reforma Universitária de 1968 que, para auxiliar o golpe de 1964, "coibia a criticidade da universidade brasileira, expulsando professores, policiando ideologicamente os novos docentes e reprimindo o movimento estudantil" (SOUZA, 1996, p. 55).

O pensamento científico se tornou parte exclusiva de um mecanismo político antidemocrático que visava apenas o desenvolvimento utilitarista do país. As atividades acadêmicas se restringiram a grades curriculares de ensino voltadas para a profissionalização dos seus estudantes.

Com o racionalismo acadêmico herdado pelos jesuítas em contraste com o cientificismo pro- 
gressista supervalorizado pelos militares, a teoria e a prática, a ciência e a universidade permaneceram em caminhos separados. Mesmo com o fim do período ditatorial em 1985 e o emprego dos modelos modernos de universidade (sobretudo o norte-americano), o processo de democratização e unificação do conhecimento nunca se deu de fato.

Como explica Souza (1996, p. 56):

[...] todas as reformas da nossa universidade não foram capazes de mudar sua perspectiva em relação ao Poder que a controlava e nem em relação à sociedade para a qual ela deveria existir. O seu legado histórico de valores positivos continua não influenciando suas ações; ao seu fardo histórico acrescentamos outras tendências desenvolvidas por ela mesma, tais como o empreguismo, o mimetismo e a hipocrisia acadêmica a impor barreiras entre os discursos universitários e a sua prática, isolando-a cada vez mais da sociedade de cujo desenvolvimento ela é vetor fundamental.

Não é por acaso que o imaginário popular do povo brasileiro polarize ciência e universidade em entidades distintas. $\mathrm{O}$ pensamento brasileiro, desde sua origem, foi construído a partir de uma base epistemológica bipartida que permanece como paradigma durante muito tempo. Não obstante, o movimento que se segue na atualidade é de tentar aproximá-las cada vez mais: a pesquisa científica, o ensino e os projetos de extensão são as atividades realizadas pela universidade que visam manter o diálogo contínuo entre a academia, a ciência e a sociedade.

Além disso, essa relação revela a necessidade de reformular a grade curricular do ensino superior a partir de um projeto nacional que priorize as exigências do país na contemporaneidade. Democratizar e unificar o conhecimento são as demandas para o futuro da universidade brasileira e não, apenas, a ciência e a universidade deverão estar unidas para que isso ocorra, como também a sociedade precisa estar presente na construção desse cenário e do diálogo.

\section{CONSIDERAÇÕES FINAIS}

O senso comum alimenta a opinião de que a ciência não possui uma relação estreita com algumas atividades acadêmicas. Essa compreensão manifesta o equívoco de encarar a ciência e a universidade como entidades polarizadas e por acreditar que as atividades praticadas em um dos âmbitos não se relacionam com as do outro.

Esse mal-entendido tem um ponto de origem: quando o cristianismo se tornou a religião oficial do ocidente, o pensamento humano seguiu por meio de um viés inteiramente metafísico e transcendental, isto é, o conhecimento do mundo é dado ao homem pelo que há de espiritual no homem, sua alma. Por mais de quatorze séculos o conhecimento oriundo das experiências humanas ficou subordinado às ordens eclesiásticas que minimizaram a sensação em detrimento da razão.

A modernidade se construiu a partir dessa supervalorização da razão no período do medievo. O retorno do pensamento científico grego em confronto com o desenvolvimento metafísico gerou um conflito epistemológico: a bipartição entre razão e sensação no interior das correntes racionalistas e empiristas originou a falsa crença de que a teoria e a prática são distintas.

Essa imagem da ciência moderna, marcada pelo positivismo e utilitarismo em contraste com a valorização do racionalismo no interior das universidades brasileiras, alimentou a opinião de que ciência e universidade não possuem uma relação intrínseca. Essa separação sustentou a opinião de que as atividades teóricas e práticas podiam ser efetuadas de modos distintos, sem haver uma interdependência entre elas. Ora, como havia percebido Kant na esteira dos gregos, a razão e a sensação são complementares e articulados. A teoria e a prática não são objetos distintos de uma realidade bipartida, mas modos complementares e articulados de compreender uma mesma realidade.

Observação: Artigo resultante dos trabalhos do Grupo de Pesquisa IMAGO (CNPq/DCI/UFPE). O estudante recebeu bolsa de monitoria da PROACAD/UFPE em 2016 para atuar nas disciplinas mencionadas no texto. 


\section{LIBRARIANSHIP, SCIENCE AND PHILOSOPHY: a necessary debate on theory and practice in the scientific-academic field}

ABSTRACT Parts from the assumption and the observation in the classroom, in the disciplines about research, science and philosophy offered in the Librarianship Course at the Federal University of Pernambuco, that a good part of the students shows a certain difficulty or some resistance in the way of understanding the relation between theory and practice at the heart of the academic-scientific field. It aims to propose a debate about the theoretical-practical relations within scientific-academic research and contribute with the production of didactic bibliography for the students use. The debate is divided into three sections: analyzes both the historical development of rationalism and empiricism and its influence on the structure of academic and scientific research; indicates how German idealism (in philosophy) and positivism (in science) promoted a division between theory and practice; and examines this bipartite heritage of thought in the Brazilian context. As an exploratory research it used the methodology of bibliographic review. As a final consideration points out that common sense has as its inheritance both the opinion, especially of students entering university, that the scientific practice has no close relationship with some academic activities. Considers also that the academic-scientific activities indicate the polarization between theory and practice, which is an inadequate contemporary opinion.

Keywords: $\quad$ Librarianship. Philosophy. Science. Practice. Theory.

\section{REFERÊNCIAS}

BAZANNELLA, S. L. A. Constituição da Cidade Moderna: pressupostos definidores da vida e suas implicações biopolíticas contemporâneas. Theoria, n. 4, p. 18-23.

CASERTANO, G. A Cidade, o Verdadeiro e o Falso em Parmênides. Kriterion, Belo Horizonte, n. 116, dez. 2007. p. 307-327.

CORNFORD, F. M. Principium Sapientiae: as origens do pensamento filosófico grego. Lisboa: Fundação Calouste Gulbenkian, 1989.

FERREIRA, A. Kant e a Revolução Copernicana do conhecimento: uma introdução. Existência e Arte, São João Del-Rei, Ano 8, n. 7, 2012. p. 140149 .

FLECK, E. C. D. A abordagem historiográfica dos séculos XIX e XX sobre a atuação de médicos e boticários jesuítas na América platina no século XVIII. História, Ciências, Saúde, Manguinhos, v. 21, n. 2, abr-jun. 2014. p. 667-685.
FREIRE, P. Pedagogia da autonomia: saberes necessários à prática docente. 33. ed. São Paulo: Paz e Terra, 1996.

PEREIRA, L. B. ENCONTRO NACIONAL DO FÓRUM DE PRÓ-REITORES DE EXTENSÃO DAS UNIVERSIDADES PÚBLICAS, 16, 2000, João Pessoa. Anais... João Pessoa: Editora da UFPB, 2000. Disponível em: <https://goo.gl/ AT8C30>. Acesso em: 28 nov. 2016

GEOGEN, P. Ciência, Sociedade e Universidade. Educação \& Sociedade, Campinas, Vol. 19, n. 63, ago. 1998. Disponível em: <https://goo.gl/ xrKNmA>. Acesso em: 31 nov. 2016.

GERMANO, M. G. Uma nova ciência para um novo senso comum. Campina Grande: Eduepb, 2011.

GILSON, E. A Filosofia na Idade Média. São Paulo: WMF Martins Fontes, 2013.

GUILOUSKI, B; COSTA, D. R. D. da; SCHLOGL, E. Tradições religiosas indígenas e afrobrasileiras. Curitiba: ASSINTEC/SME, 2007. 
Disponível em: <https://goo.gl/75SqBT>. Acesso em: 31 nov. 2016.

HADOT, P. O que é a Filosofia Antiga? 5. ed. São Paulo: Loyola, 2011.

HEATH, T. Aristarchus of Samos: The Ancient Copernicus. New York: Dover Pubns, 1981.

HUME, D. Investigação Sobre o Entendimento Humano. São Paulo: Abril Cultura, 1973. (Coleção Os pensadores, v. 23).

JOSEPH, S. M. The Trivium: The Liberal Arts of Logic, Grammar, and Rhetoric. Philadelphia: Firt Paul Dry Books Edition, 2002.

KAHN, C. H. Pitágoras e os Pitagóricos: uma breve história. São Paulo: Loyola, 2007.

LEMOS, F. [Sobre reformas no sistema de ensino] de Wilhelm von Humboldt. Revista Brasileira de História da Educação, Campinas, v. 11, n. 1, janabr, 2011. p. 207-241.

NAPOLITANO, M. O Golpe de 1964 e o regime militar brasileiro: apontamentos para uma revisão historiográfica. Contemporânea, Salvador, v. 2, ano. 2, 2011. p. 209-218.

NERVO, A. C. S; FERREIRA, F. L. A importância da pesquisa como princípio educativo para a formação científica de educandos do Ensino Superior. Educação em Foco, Minas Gerais, n. 7, 2015. p. 31-40.

PEREIRA, E. M. A. A universidade da modernidade nos tempos atuais. Avaliação, Sorocaba, v. 14, n. 1, mar. 2009. p. 29-52.

PLATÃO. Diálogos socráticos: Fedro, Eutífron, Apologia de Sócrates, Críton, Fédon. São Paulo: Edipro, 2015.

PIMENTEL, L B. O projeto da ciência moderna e os caminhos epistemológicos da economia: marginalismo e materialismo dialético. Rio de Janeiro, 2013. (Dissertação).

PÓVOA, A. C. S, et al. Paradigma Positivista: as diferentes faces de um ilustre desconhecido. ENCONTRO DE ESTUDOS
ORGANIZACIONAIS DA ANPAD. 7, Curitiba: Eneo, 2012. p. 1-16.

REALE, G; ANTISERI, D. História da filosofia: Antiguidade e Idade Média. São Paulo: Paulus, 1990. v. 1.

História da filosofia: do Humanismo a Kant. São Paulo: Paulus, 2007. v. 2.

RONAN, C. A História Ilustrada da Ciência: das origens à Grécia. Rio de Janeiro: Jorge Zahar, 1987. v. 1.

ROSA, C. A. P. História da Ciência: da Antiguidade ao Renascimento científico. Brasília: Fundação Alexandre de Gusmão, 2012. v. 1.

SALCEDO, D. A. A ciência nos selos postais comemorativos brasileiros: 1900-2000. Recife: EDUFPE, 2010.

SANTOS, I. E. Manual de métodos e técnicas de pesquisa científica. 7. ed. Niterói: Impetus, 2010.

SOUZA, J. G. Evolução Histórica da Universidade Brasileira: Abordagens Preliminares. Revista da Faculdade de Educação, Campinas, v. 1, n. 1, ago. 1996. p. 42-58.

ZATTI, V. Autonomia e Educação em Immanuel Kant \& Paulo Freire. Porto Alegre: Edipucrs, 2007. 